\title{
AVALIAÇÃo MICROBIOLÓGICA DA ÁGUA DO AÇUDE SABIÁ DO MUNICÍPIO DE MERUOCA - CE
}

Francisco Fábio Pereira de SOUZA ${ }^{1, *}$

Andréa Maria NEVES ${ }^{2}$

Maria Gleiciane Soares COUTINHO ${ }^{3}$

Anny Sampaio SILVA ${ }^{4}$

Raquel Oliveira dos Santos FONTENELLE ${ }^{5}$

${ }^{1-4}$ Graduados em Ciências Biológicas pela Universidade Estadual Vale do Acaraú (UVA);
${ }^{5}$ Prof $^{\mathrm{a}}$. Dr ${ }^{\mathrm{a}}$. do Curso de Ciências Biológicas da Universidade Estadual Vale do Acaraú (UVA)
${ }^{*}$ Autor correspondente: fabiosouzawin@live.com

Recebido em: 29/03/2016 - Aprovado em: 10/03/2017 - Disponibilizado em: 01/07/2017

\section{RESUMO}

A água é um elemento essencial para a manutenção da vida na Terra e está presente em diversos segmentos da vida do homem, que depende do seu fornecimento para a realização da maioria de suas atividades diárias. O presente estudo teve como objetivo avaliar a qualidade microbiológica da água do Açude Sabiá do Município de Meruoca no Estado do Ceará. Foram coletadas 04 amostras de três pontos distintos do açude, perfazendo um total de 12 amostras, que foram submetidas à determinação do Número Mais Provável (NMP) para Coliformes Totais, Coliformes Termotolerantes e à quantificação de bactérias aeróbias mesófilas.O NMP para coliformes totais variou de 8,0x10a >1,6x10 ${ }^{3} \mathrm{CT} / 100 \mathrm{~mL}$ e

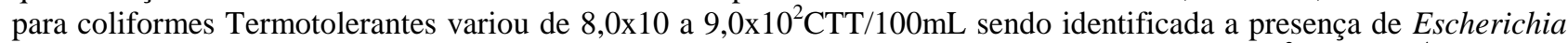
coli em todas as amostras. Os resultados para bactérias aeróbias mesófilas variaram de $1,2 \times 10^{2}$ a $8,6 \times 10^{4} \mathrm{UFC} / \mathrm{mL}$. Todos os resultados estão em desacordo com a legislação vigente. Portanto, a água do Açude Sabiá encontra-se imprópria para o consumo humano indicando, assim, a necessidade de adoção urgente de medidas corretivas.

Palavras chaves: Açude do Sabiá.Coliformes totais.Escherichia coli. Meruoca.

\begin{abstract}
Water is an essential element for the maintenance of life on Earth and is present in various segments of human life, which depends on the supply to achieving the most of their daily activities. This study aimed to evaluate the microbiological quality of water Sabiá Dam Meruoca municipality in the State of the Ceará. Four samples were collected from three different points of the Dam, making a total of 12 samples, which were submitted to determine the Most Probable Number (MPN) for Total Coliform, Thermotolerants Coliforms and quantification of mesophilic aerobic bacteria. The NMP for total coliforms ranged from the 8,0x10 to $>1,6 \times 10^{3} \mathrm{CT} / 100 \mathrm{~mL}$ and Thermotolerant coliforms ranged from $9,0 \times 10^{2}$ to $8,0 \times 10$ CTT/100mLand the presence of Escherichia coliwas identified in all samples. The results for mesophilic aerobic bacteria ranged from $1,2 \times 10^{2}$ to $8,6 \times 10^{4} \mathrm{CFU} / \mathrm{mL}$. All results are at odds with the law. Therefore, the water Sabiá Dam is unfit for human consumption thus indicating the need for urgent corrective action.
\end{abstract}

Key words: Sabiá Dam. Total coliforms.Escherichia coli.Meruoca.

\section{INTRODUÇÃO}

A água é um elemento essencial para a manutenção da vida na Terra e está presente em diversos segmentos da vida do homem, que depende do seu fornecimento para beber, se alimentar e para realizar a maioria de suas atividades diárias. $\mathrm{O}$ aumento pela demanda d'água, ocasionado pelo constante aumento da população mundial, aliado à crescente 
contaminação dos recursos hídricos, têm tornado sua disponibilidade cada vez mais escassa (VEGA et al., 1998).

Outro fator que pode comprometer o abastecimento de água em algumas regiões é a irregularidade com que as chuvas acontecem. Em regiões semiáridas, como por exemplo a região Nordeste do país, que também enfrentam períodos de seca, a escassez de água ainda é um problema muito grave. Diante disso, o governo vem investindo à décadas em alternativas que visam garantir um melhor abastecimento de água e minimizar os problemas causados pela escassez da mesma. À exemplo dessas alternativas tem-se o Departamento Nacional de Obras Contra as Secas (DNOCS), um órgão responsável pela construção de açudes criado a mais de cem anos (ALVES et al.,2014). Outras medidas implementadas foram a perfuração de poços profundos e, mais recentemente, a distribuição de cisternaspara o armazenamento de água da chuva. No entanto, mesmo diante dessa preocupação para com a garantia no abastecimento d'água, pouco se pensou nos aspectos relacionados com a qualidade dessa água (BRITO, L. et al., 2005).

A portaria $n^{\circ} 2914 / 2011$ do Ministério da Saúde estabelece que a água própria para o consumo humano deve obedecer a um padrão de potabilidade e apresentar parâmetros microbiológicos, físico-químicos e radioativos aceitáveis de modo que não ofereça riscos à saúde dos consumidores (BRASIL, 2011). Uma água que se apresente fora desses parâmetros confere um problema ambiental grave e o seu consumo pode comprometer a saúde humana tendo em vista os efeito deletérios que esta pode causar (CETESB, 2009).

A contaminação dos corpos d'água por resíduos humanos é um problema gravíssimo e pode ocorrer diretamente na fonte, durante a distribuição ou ainda durante o armazenamento da água quando realizados sob condições higiênico-sanitárias precárias (BARBOSA; LAGE; BARDARÓ, 2009; MORAES; JORDÃO, 2002). Dessa forma, é de suma importância a realização do monitoramento da qualidade microbiológica da água destinada ao consumo humano como forma de minimizar os riscos à saúde dos consumidores.

Normalmente esse monitoramento é realizado através de indicadores microbiológicos de uso universal que utilizam microrganismos tipicamente encontrados no trato gastrointestinal de humanos e animais homeotérmicos, como os coliformes totais e Termotolerantes (SHIBATA et. al, 2004).De acordo com a Agência Nacional da Vigilância Sanitária (ANVISA) a água própria para o consumo humano sugere a ausência de coliformes Termotolerantes, com destaque para Escherichia coli, em cada 100mL de água e positividade de até $5 \%$ para coliformes totais (BRASIL, 2011). 
Os micro-organismos pertencentes ao grupo dos coliformes têm o formato de bastonetes Gram-negativos e pertencem à família Enterobacteriaceae. São característicos pela facilidade com que se propagam pela natureza e por serem encontrados normalmente nas fezes humanas. Tais características somadas à fácil identificação em laboratório fazem com que esses micro-organismos sejam usados como indicadores microbiológicos para analisar a qualidade de águas (NASCIMENTO; ARAÚJO, 2013).

Segundo a Organização Mundial da Saúde, $80 \%$ das doenças que atingem os países subdesenvolvidos são causadas por micro-organismos patogênicos veiculados pela água contaminada. Nesses países as doenças de veiculação hídrica, de origem entérica animal ou humana, têm causado inúmeros surtos e são responsáveis por altas taxas de mortalidade infantil (WHO, 2004).

A água armazenada em poços rasos ou açudes normalmente não recebem tratamento adequado e encontram-se mais susceptível à contaminação microbiana podendo causar sérios riscos à saúde da população que faz o consumo desta água para beber e preparar alimentos (BRITO, S. et al, 2011). No Nordeste brasileiro esses reservatórios constituem a principal fonte de abastecimento d’água.

O Açude Sabiá constitui a principal fonte de abastecimento d'água do Município de Meruoca e, portanto, tem vital importância na manutenção da qualidade de vida local. Por ter sido construído em uma área antes habitada e que foi desapropriada em razão de sua implantação, a população não está segura da qualidade da água do açude e teme que as fossas sanitárias que haviam no local possam estar comprometendo a qualidade da mesma. Outro fator preocupante é que a distribuição dessa água ocorre, em sua maioria, de maneira inadequada e sem receber tratamento adequado o que pode significar riscos à saúde da população beneficiada caso a mesma não se apresente em condições microbiológicas satisfatórias como se suspeita.

Muitos dos distritos do Município de Meruoca não têm acesso à saneamento básico nem à água encanada e tratada e, por isso,nesses locais o abastecimento d'água é realizado através de carros-pipa e armazenada sem cuidados higiênico-sanitários adequados. Além disso, a população desses distritos, normalmente, usam a água do açude Sabiá para preparar alimentos e para beber sem antes submetê-la à um tratamento que possa diminuir sua carga microbiana. Embora a água seja considerada essencial para os seres vivos,esta pode se tornar fonte de graves problemas de saúde pública quando funciona como um veículo de transmissão de microorganismos patogênicose não é tratada (DANTAS et al, 2010). Sabe-se que é um direito das pessoas terem acesso a água não só 
em quantidade suficiente, mas também em qualidade satisfatória.

Diante do exposto, o presente estudo teve por objetivo avaliar a qualidade microbiológica da água do Açude Sabiá através da determinação do Número Mais provável para Coliformes Totais e Termotolerantes e da contagem de microorganismos aeróbios mesófilos.

\section{MATERIAL E MÉTODOS}

\section{1 Área de estudo}

O Município de Meruoca está localizado no Noroeste do estado do Ceará à aproximadamente 717 metros de altitude e a 248 quilômetros da capital Fortaleza fazendo fronteira com os municípios de Sobral, Massapê e Alcântara. Segundo dados do IBGE, em 2010, a população de Meruoca era estimada em 13.693 habitantes. Suas muitas riquezas naturais e o clima agradável fazem do Município cearense uma área de refúgio para quem procura tranquilidade e descanso. Apesar de estar localizada em área serrana e possuir muitos riachos, lagos e alguns açudes, nos últimos anos o Município tem enfrentado dificuldades no abastecimento de água durante os períodos de estiagem.

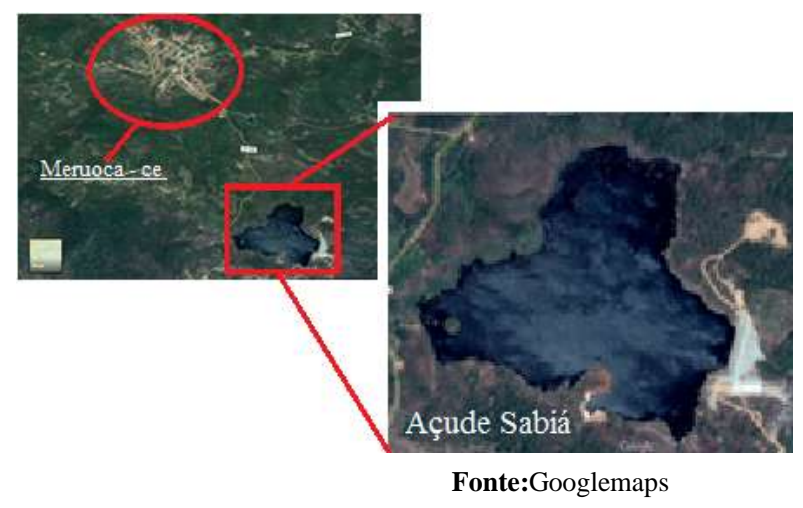

Figura 1: Imagens de satélite mostrando a sede do Município de Meruoca e o Açude Sabiá.

\subsection{Amostragem}

Foram escolhidos de forma estratégica três pontos distintos do açude para realização das coletas, que ocorreram no período de Março à Julho de 2015. O primeiro ponto de coleta (ponto A) localiza-se próximo à barreira do açude e caracteriza-se como uma área utilizada pelas pessoas para fins recreativos e atividade pesqueira. $\mathrm{O}$ segundo ponto de coleta (ponto B) localiza-se entre a barreira do açude e o seu extremo oposto, sendo caracterizado como uma área de lavagem de roupas,de água turva e com lixo sob água e margens. O terceiro ponto de coleta (ponto C) localiza-se na extremidade oposta à barreira do açude e é uma área onde há a coleta d'água por carros-pipa e também onde encontra-se instalada uma adutora que distribui a água que abastece o Município.

Foram coletas de forma asséptica 04 (quatro) amostras de cada um dos três pontos perfazendo um total de 12 (doze) amostras. As amostras coletadas foram armazenadas em tubos âmbar estéreis com capacidade para 
$1000 \mathrm{~mL}$, acondicionadas em uma caixa isotérmica e transportadas para o Laboratório de Microbiologia da Universidade Estadual Vale do Acaraú (UVA) onde procedeu-se imediatamente com as análises.Todas as coletas foram realizadas no período da manhã entre 06 e 08 horas e o tempo de duração entre a coleta e o início das análises variou de uma à duas horas.

\subsection{Preparo das amostras e teste presuntivo}

As análises foram realizadas conforme o estabelecido pelo Standard methods for the examination of water and wastewater (APHA, 2012). As amostras foram preparadas em três diluições: $10^{1}, 10^{-1}$ e $10^{-2}$. Para primeira diluição $\left(10^{1}\right)$ retirou-se $10 \mathrm{~mL}$ da amostra e fez-se o inoculo numa primeira série de cinco tubos de ensaio com $5 \mathrm{~mL}$ cada de Caldo Lactosado (CL) em concentração dupla com Durham invertido.Para a segunda diluição $\left(10^{-1}\right)$ retirou-se $1 \mathrm{~mL}$ da amostra e fez-se o inoculo numa segunda série de cinco tubos com5mL cada de CL em concentração simples com Durham invertido. E para terceira diluição $\left(10^{-2}\right)$ retirou-se $1 \mathrm{~mL}$ da amostra, inoculou-se o em $9 \mathrm{~mL}$ de solução salina estéril à $0,85 \%$, fez-se a homogeneização e em seguida retirou-se $1 \mathrm{~mL}$ da solução e fez-se o inoculo numa terceira série de cinco tubos com $5 \mathrm{~mL}$ cada de CL em concentração simples e com Durham invertido.
O uso do Caldo Lactosado permite avaliar a capacidade dos micro-organismos em fermentar a lactose evidenciada com a produção de gás dentro dos Durham e/ou meio turvo. Após inoculados, os tubos de Caldo Lactosado foram incubados em estufa bacteriológica a $35^{\circ} \mathrm{C}$ por 48 horas. Passado esse período realizou-se a leitura dos tubos. Foram considerados positivos os tubos que apresentaram a formação de bolhas dentro do Durham e/ou meio turvo.

\subsection{Contagem de coliformes totais e} coliformes Termotolerantes

A contagem de coliformes totais (CT) e coliformes Termotolerantes (CTT) foi realizada utilizando-se a técnica do Número Mais Provável(APHA, 2012). Para a enumeração de CT retirou-se, com o auxílio de uma alça de platina, uma alíquota de cada cultura positiva em Caldo Lactosado e fez-se o inoculo em séries de 5 tubos com $5 \mathrm{~mL}$ cada de Caldo Bile Verde Brilhante (BVB) contendo Durham invertido. Após esse procedimento os tubos inoculados foram incubados em estufa bacteriológica à $35^{\circ} \mathrm{C}$ por 48 horas.

Para a enumeração de CTT também retirou-se uma alíquota de cada cultura positiva em Caldo Lactosado, porém fez-se o inoculo em séries de 5 tubos com $5 \mathrm{~mL}$ cada de Caldo Escherichia coli (EC) com Durham invertido. Após esse procedimento os tubos 
inoculados foram colocados em banho-maria à $45^{\circ} \mathrm{C}$ por 48 horas.

Foram considerados positivos os tubos que apresentaram formação de bolhas dentro do Durham após o período de incubação. A determinação do Número Mais Provável (NMP) para CT e CTT foi realizada mediante consulta à Tabela do NMP que estabelece um número estimado de acordo com a quantidade de tubos positivos para cada diluição de cada amostra.

\subsection{Identificação dos micro-} organismos isolados

A identificação dos micro-organismos pertencentes à família Enterobacteriaceae foi realizada através do teste bioquímico ImVic de acordo com Koneman et al. (2008). Utilizou-se para este teste as culturas positivas para o Caldo EC procedendo-se da seguinte forma: fez-se o repique de uma alíquota da cultura positiva para placas de Petri contendo meio Eosin Methylene Blue Agar (EMB) que em seguida foram incubadas em estufa bacteriológica a $35^{\circ} \mathrm{C}$ por 24 horas. Após esse período fez-se o isolamento de colônias suspeitas de Escherichia coli em tubos com meio TrypticSoy Agar (TSA) derreado e incubou-se por 24 horas a $35^{\circ} \mathrm{C}$. As culturas crescidas em TSA foram submetidas ao teste bioquímico ImVice a identificação dos micro-organismos foi realizada consultando a tabela de testes bioquímicos para diferenciação de espécies bacterianas.

\subsection{Quantificação de micro-} organismos aeróbios mesófilos

Para quantificar os micro-organismos aeróbios mesófilos utilizou-se a técnica de "Pour Plate" procedendo-se da seguinte forma: preparou-se as amostras em três diluições, $10^{-1}, 10^{-2}$ e $10^{-3}$; retirou-se $1 \mathrm{~mL}$ de cada diluição, adicionou-se em tubos com $15 \mathrm{~mL}$ de meio Plate Count Agar (PCA) que em seguida foram derramados em placas de Petri estéreis, homogeneizados em suaves movimentos em forma de oito e deixados em repouso até a completa solidificação. As placas foram incubadas em estufa bacteriológica a $35^{\circ} \mathrm{C} / 24 \mathrm{~h}$ e em seguida realizou-se a contagem das Unidades Formadoras de Colônia (UFC) com o auxílio de um contador de colônias. Todo o procedimento foi realizado em duplicata.

\section{RESULTADOS E DISCUSSÃO}

Os resultados obtidos mostraram que $100 \%$ das amostras analisadas apresentaram índices elevados para coliformes totais,coliformes Termotolerantese bactérias aeróbias mesófilas. Além disso, todas as amostras também apresentaram contaminação por Escherichia coli (Tabela 1).

O Número Mais Provável de Coliformes Termotolerantes nas amostras analisadas variou de $2,7 \times 10 \mathrm{a}$ 
9,2x $10^{2}$ CTT/100mL. A Portaria n ${ }^{\circ}$ 2914/2011

do Ministério da Saúde (MS) estabelece que a água própria para o consumo humano deve estar isenta de coliformes Termotolerantes ou E. coli em cada $100 \mathrm{~mL}$. De acordo com os resultados obtidos todas as amostras apresentaram-se em desacordo com a legislação brasileira. Araújo et al. (2014),ao analisarem a água do açude Forquilha - CE, registraram para coliformes Termotolerantes valores que variaram de 2,0x10 a $1,3 \times 10^{2}$ CTT/100mL sendo também identificada a presença de E. coli em todas as amostras analisadas configurando, portanto, uma água imprópria para o consumo humano.

O Número Mais Provável para coliformes totais nas amostras analisadas

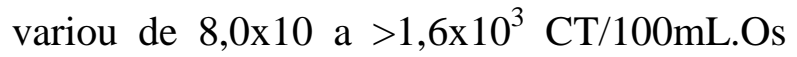
maiores valores foram registrados para os pontos $\mathrm{B}$ e $\mathrm{C}$ onde foi observado a presença de lixo sob às águas e margens, água de coloração barrenta, área de lavagem de roupa, banho e pesca. A portaria 2914/2011 do MS não estabelece um limite de tolerância para coliformes totais em amostras d'água, entretanto sugere que quando detectada a presença destes deve-se adotar medidas de caráter corretivo e preventivo seguida da realização de novas análises até que se obtenha um resultado satisfatório. Nascimento et al. (2007), afirmam que a presença de coliformes totais na água pode ser indícios de falhas em seu armazenamento, distribuição ou tratamento.
O número de bactérias aeróbias mesófilas variou de $1,2 \times 10^{2}$ a $8,6 \times 10^{4}$ UFC/ml. De acordo com a Portaria 2914/2011 do MS, a água própria para o consumo humano deve obedecer ao limite máximo de 500 Unidades Formadoras de Colônias por mililitro de água. Diante disso, todas as amostras analisadas encontravam-se impróprias para o consumo humano. Valores semelhantes foram encontrados por Alves et al. (2014), ao analisarem a água do Açude Edson Queiroz do Município de Santa Quitéria, no estado do Ceará, onde os valores encontrados para bactérias aeróbias mesófilas variaram de $1,0 \times 10^{4} \mathrm{UFC} / \mathrm{ml}$ a $1,4 \times 10^{5}$ UFC/ml. De acordo com Sabioni e Silva (2006), as bactérias aeróbias mesófilas são encontradas normalmente na água, porém, quando em quantidades elevadas, podem causar sérios riscos à saúde do consumidor tendo em vista sua capacidade de atuação como patógenos secundários.

Das doze amostras analisadas foram isoladas 76 cepas da família Enterobacteriaceae, que é considerada uma das famílias de bactérias de maior importância para o homem e que abriga patógenos que estão entre os principais agentes causadores de infecções hospitalares e infecções intestinais em vários países (ARAÚJO, 2014). Dentre as 76 cepas isoladas (100\%), 44 (58\%) correspondiam a Escherichia coli, 11 (14\%) a Klebisiella pneumoniae, $8(11 \%)$ a Serratia liquefaciens, 5 (7\%) a Enterobacter 
aerogenes, $4(5 \%)$ a Hafnia alveie $4(5 \%)$ a Proteus vulgaris (Gráfico 1).

Tabela 1 - Número Mais Provável (NMP) por 100mL de água para coliformes totais (CT), coliformes Termotolerantes (CTT), pesquisa de Escherichia coli e quantificação de micro-organismos aeróbios mesófilos (BAM) nas águas do Açude Sabiá do Município de Meruoca-CE.

\begin{tabular}{ccccc}
\hline & NMP/ & NMP/1 & E. & BAM \\
Amostra & $100 \mathrm{~mL}$ & $00 \mathrm{~mL}$ & $\begin{array}{c}\text { coli } \\
\text { UFC } / \mathrm{mL}\end{array}$ \\
& $\mathrm{CT}$ & $\mathrm{CTT}$ & & \\
\hline A I & $3,0 \times 10^{2}$ & $9,0 \times 10^{2}$ & + & $5,5 \times 10^{2}$ \\
A II & $5,0 \times 10^{2}$ & $4,1 \times 10$ & + & $3,1 \times 10^{2}$ \\
A III & $8,0 \times 10$ & $3,5 \times 10^{2}$ & + & $1,5 \times 10^{3}$ \\
A IV & $9,0 \times 10^{2}$ & $8,0 \times 10$ & + & $1,8 \times 10^{3}$ \\
B I & $2,2 \times 10^{2}$ & $2,2 \times 10^{2}$ & + & $3,7 \times 10^{3}$ \\
B II & $1,6 \times 10^{3}$ & $2,7 \times 10$ & + & $1,2 \times 10^{2}$ \\
B III & $1,2 \times 10^{2}$ & $1,4 \times 10^{2}$ & + & $2,5 \times 10^{3}$ \\
B IV & $3,5 \times 10^{2}$ & $3,4 \times 10$ & + & $9,8 \times 10^{3}$ \\
C I & $1,6 \times 10^{3}$ & $1,5 \times 10^{2}$ & + & $4,6 \times 10^{2}$ \\
C II & $1,6 \times 10^{3}$ & $3,0 \times 10^{2}$ & + & $1,5 \times 10^{3}$ \\
C III & $1,6 \times 10^{3}$ & $3,5 \times 10^{2}$ & + & $8,6 \times 10^{4}$ \\
C IV & $3,5 \times 10^{2}$ & $5,0 \times 10$ & + & $1,8 \times 10^{3}$
\end{tabular}

Fonte: O autor, 2015

*Unidades Formadoras de Colônias

A Escherichia coli faz parte da microbiota normal de animais de sangue quente sendo encontrada exclusivamente no trato intestinal desses animais, portanto sua presença na água e em alimentos é um forte indicador de contaminação de origem fecal.A E. coli é uma bactéria de alta periculosidade e é a causadora de muitas enfermidades como, por exemplo, meningite neonatal, gastroenterite, sepse e infecções urinárias. Além disso, algumas linhagens dessa bactéria produzem enterotoxinas que causam a chamada diarreia do viajante e também algumas doenças de origem alimentar. Outros micro-organismos tão perigosos quanto, como Klebisiella pneumoniae, Serratia liquefaciens, Proteus vulgaris, os sorotipos de Salmonella spp. e entre outros, também podem causar graves infecções em animais e humanos e todos podem ser transmitidas através da água contaminada (TORTORA et al, 2006).

Assim como a E. coli, a Klebsiella pneumoniae é uma bactéria de grande importância para a saúde humana sendo frequentemente relatada em casos de infecções hospitalares em pacientes imunodeprimidos podendo causar infecções urinária e respiratória. Além do trato intestinal, essa bactéria também pode habitar outras regiões do corpo humano como, por exemplo, a nasofaringe, onde favorece o desenvolvimento de pneumonias (TRABULSI; ALTERTHUM, 2008).

Os gêneros Enterobacter, Citrobacter, Providencia, Serratia, Hafnia e Proteus também constituem parte da flora intestinal do organismo humano e de outros animais de sangue quente e também vivem no solo e na água. Normalmente os micro-organismos pertencentes à estes gêneros não são capazes de invadir outras partes do corpo humano nem causar infecções. No entanto,em condições de um sistema imunológico debilitado, podem causar infecções oportunistas como septicemia e infecções no trato gênito-urinário (NASCIMENTO; ARAÚJO, 2013). 
Gráfico 1 - Distribuição das cepas de coliformes Termotolerantes identificadas ema mostras de água do Açude Sabiá do Município de Meruoca-CE.

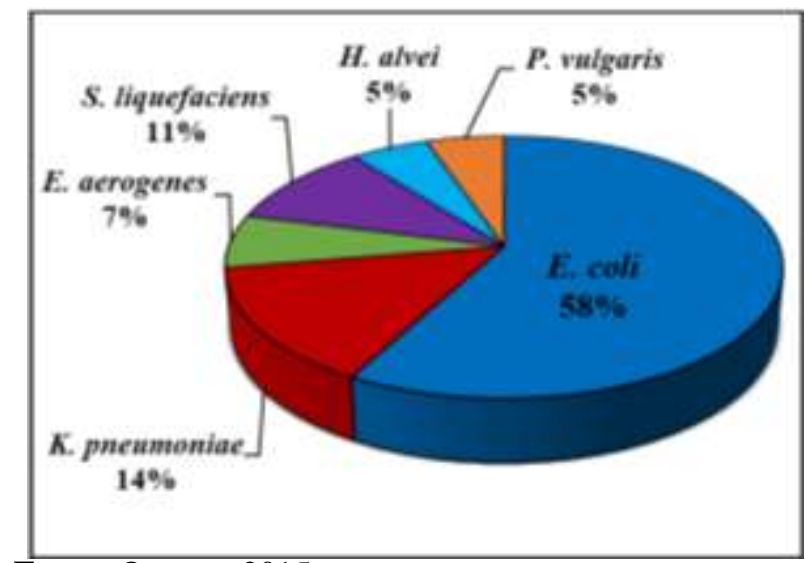

Fonte: O autor, 2015.

\section{CONCLUSÃO}

Diante dos resultados obtidos concluise que a água do Açude Sabiá encontra-se em desacordo com os padrões microbiológicos estabelecidos pela legislação brasileira (MS,

\section{REFERÊNCIAS}

ALVES, F. R. L.; AGUIAR, F. L. L.; ARAÚJO, A. B.; MELO, M. B.; SALES, J. C.;FONTENELLE, R. O. S. Avaliação microbiológica da água do açude Edson Queiroz no Município de Santa Quitéria, Ceará. Revista Higiene Alimentar, v. 28, n. 238/239, p.89-92, 2014.

APHA - American Public Health Association. Standard methods for the examination of water and wastewater. $22^{\mathrm{a}} \mathrm{ed}$. Washington: APHA, 2012, 9-224p.

ARAÚJO, A. B.; SALES, J. C.; FONTENELLE, R. O. S.; ALVES, F. R. L.;AGUIAR, F. L. L. Qualidade microbiológica e avaliação do estado trófico de amostras de água do açude Forquilha - CE. Enciclopédia Biosfera, Centro científico conhecer, Goiânia, v. 10, n. 18, p. 3368, 2014.
Portaria $n^{\circ}$ 2914/2011). Os altos índices de coliformes totais, coliformes Termotolerantes e bactérias aeróbias mesófilas encontrados na água do açude estudado, podem estar diretamente relacionados com a disposição de resíduos orgânicos provenientes de atividades humanas e animais que, quando realizada de maneira inadequada, podem contaminar os corpos d'água oferecendo, assim, riscos à saúde humana em decorrência do consumo da água contaminada.

Tais índices sugerem a necessidade de se realizar o monitoramento da qualidade da água do açude bem como adotar medidas urgentes de caráter corretivo como forma de minimizar os riscos à saúde dos consumidores.

BARBOSA, D. A.; LAGE, M. M.; BARDARÓ, A.C. Qualidade microbiológica dos bebedouros de um campus universitário de Ipatinga, Minas Gerais. Revista Digital de Nutrição, Ipatinga, v. 3, n. 5, p. 505-517, ago-dez, 2009.

BRASIL. Ministério da Saúde. Portaria $\mathrm{n}^{\circ}$ 2.914 de 12 de Dezembro de 2011.Dispõe sobre os procedimentos de controle e de vigilância da qualidade da água para consumo humano e seu padrão de potabilidade. D.O.U., Brasília, 2011.

BRITO, L. T. L.; ANJOS, J. B.; PORTO, E. R.; CAVALCANTI, N. B.;GNADLINGER, J.; XENOFONTE, G. H. S. Avaliação da qualidade das águas de açudes no Município de Petrolina e Ouricurí, PE e Canudos Uauá, BA: estudo de caso. $5^{\circ}$ Simpósio Brasileiro de 
Captação e Manejo de Água de Chuva, Teresina, PI, Jul. 2005.

BRITO, S. A.; FERNANDES, C. N.; SOUZA, H. H. F.; TELES, G.G. S.; SANTOS,P. F.; VERAS, H. N. H.; PINHO, A. I. Avaliação físico-química e microbiológica da água "in Natura", distribuída pela rede de abastecimento e do Reservatório Ossean Araripe/Crato-Ce.

Caderno de Cultura e Ciências, Crato, v. 2, n. 2, p. 1-7, 2011.

\section{CETESB - Centro Tecnológico de}

Saneamento Básico. São Paulo. 2009.

Disponível em: $\langle\underline{\text { http://www.cetesb.sp.gov.br }>}$

Acesso em: 25/06/2015.

DANTAS, A. K. D.; SOUZA, C.; FERREIRA, M. S.; ANDRADE, M. A.;ANDRADE, D.; WATANABE, E. Qualidade microbiológica da água de bebedouros destinada ao consumo humano. Revista Biociências, v. 16, n. 2, 2010.

KONEMAN, E. W.; ALLEN, S. D.; JANDA, W.; WINN, W.Jr.; PROCOP, G.;

CHRECKENBERGER, P.; WOODS, G. Diagnóstico Microbiológico: texto e atlas colorido. 6. Ed. Guanabara Koogan, 2008. $1760 \mathrm{p}$.

NASCIMENTO, M. S. V.; CARDOSO M. O.; OLIVEIRA, E. H.; CARVALHO, O.B. Análise bacteriológica da água no estado do Piauí nos anos de 2003 e 2004. Revista

HigieneAlimentar, São Paulo, v. 21, n.151, p. $99-103,2007$.

NASCIMENTO, V. F. S.; ARAÚJO, M. F. F. Ocorrência de bactérias patogênicas oportunistas em um reservatório do Semiárido do Rio Grande do Norte, Brasil. Revista de Ciências Ambientais, Canoas, v. 7, n. 1, p. 91-104, 2013.

MORAES, D. S. L.; JORDÃO, B. Q.

Degradação de recursos hídricos e seus efeitos sobe a saúde humana. Revista Saúde

Pública, v. 3, p. 370-374, 2002.
SHIBATA, T.; SOLO-GABRIELE, H. M.; FLEMING, L. E.; ELMIR, S. Monitoring marine recreational water quality using multiple microbial indicators in an urban tropical environment. WaterResearch, v.38, p. 3119-3131, 2004.

SABIONI, J. G.; SILVA, I.T. Qualidade microbiológica de águas minerais comercializadas em Ouro Preto, MG. Revista Higiene Alimentar, São Paulo, v. 20, n. 143, p. 72-74, 2006.

TORTORA, G. J.; FUNKE, B. R.; CASE, C. L. Microbiologia. 8. ed. Porto Alegre,Artmed, 2006. 894p.

TRABULSI, L. R.; ALTERTHUM, F. Microbiologia. 5. Ed. São Paulo, Atheneu, 2008.760 p.

VEJA, M.; PARDO, R.; BARRDO, E.; DEBAN, L. Assessment of seasonal and polluting effects on the quality of the river water by exploratory data analysis. Water Research, v. 32, n.12, p. 3581-3592, 1998.

WHO - World Health Organization. Guidelines for drinking water quality. In: Recommendation. 3. Ed. Geneve, Chapter 7. v. 1, p. 121-144, 2004. Disponível em: $<$ http://www.who.org > Acesso em: 25/06/2015. 